Article

\title{
Same Diet, Different Strategies: Variability of Individual Feeding Habits across Three Populations of Ambrosi's Cave Salamander (Hydromantes ambrosii)
}

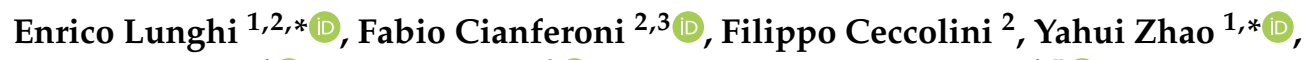

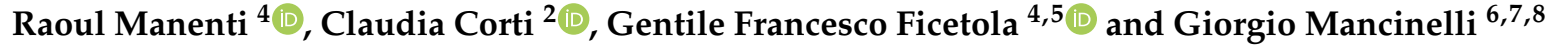 \\ 1 Key Laboratory of the Zoological Systematics and Evolution, Institute of Zoology, Chinese Academy of \\ Sciences, Beijing 100101, China \\ 2 Museo di Storia Naturale dell'Università degli Studi di Firenze, Museo "La Specola”, 50125 Firenze, Italy; \\ cianferoni.fabio@gmail.com (F.C.); ceccolinif@virgilio.it (F.C.); claudia.corti@unifi.it (C.C.) \\ 3 Istituto di Ricerca sugli Ecosistemi Terrestri, Consiglio Nazionale delle Ricerche, \\ 50010 Sesto Fiorentino (Firenze), Italy \\ 4 Dipartimento di Scienze e Politiche Ambientali, Università degli Studi di Milano, 20133 Milano, Italy; \\ raoulmanenti@gmail.com (R.M.); francesco.ficetola@gmail.com (G.F.F.) \\ 5 Laboratoire d'Écologie Alpine (LECA), CNRS, University Grenoble Alpes, 38000 Grenoble, France \\ 6 Dipartimento di Scienze e Tecnologie Biologiche ed Ambientali (DiSTeBA), Università del Salento, \\ 73100 Lecce, Italy; giorgio.mancinelli@unisalento.it \\ 7 Istituto per le Risorse Biologiche e le Biotecnologie Marine (IRBIM), Consiglio Nazionale delle \\ Ricerche (CNR), 08040 Lesina (Foggia), Italy \\ 8 CoNISMa, Consorzio Nazionale Interuniversitario per le Scienze del Mare, 00196 Roma, Italy \\ * Correspondence: enrico.arti@gmail.com (E.L.); zhaoyh@ioz.ac.cn (Y.Z.)
}

Received: 14 March 2020; Accepted: 3 May 2020; Published: 6 May 2020

\begin{abstract}
European cave salamanders of the genus Hydromantes are a group of eight species endemic to Italy and south-eastern France. Knowledge on the trophic niche of European Hydromantes is poor, and the few available studies only partially investigate their feeding habits. We performed an in-depth study on the trophic niche of the Ambrosi's cave salamander (H. ambrosii), assessing the potential divergences among three different populations. All the populations had a similar diet composition, showing a wider trophic niche in fall compared to spring. In only one population, "true specialists" were present; however, in all three populations, generalist individuals always represented the larger proportion. Interspecific and intraspecific competition did not play an important role in determining individual dietary specialisation in H. ambrosii; contrarily, the characteristics of the surrounding environment seemed to be an important factor. The best body conditions were observed in the population located in the site where the non-arboreal vegetation cover was the highest. Besides providing new information on the trophic niche of $H$. ambrosii, we here showed that studies encompassing both intrinsic and extrinsic factors at the population level are needed to fully understand the trophic dynamics occurring among European cave salamanders.
\end{abstract}

Keywords: individual diet specialization; ecological opportunity; diet; plethodontid; cave biology

\section{Introduction}

European plethodontid salamanders (genus Hydromantes; see [1] for taxonomic discussion) are composed of eight species distributed in Italy and in Provencal France [2]. European Hydromantes all show allopatric distributions [2,3] with one exception. Two mainland species, H. ambrosii and H. italicus, 
overlap in a small area corresponding, respectively, to their most southern and northern distributions; this has naturally led to the occurrence of hybrid populations [4]. Although not being strictly cave species [2], the se relatively small salamanders are often found in caves and other subterranean habitats, where they seek specific microclimatic conditions [5]. Plethodontid salamanders lack lungs and mainly breath through the skin [6]; to keep their respiration efficient, the y need relatively low temperatures and high moisture [7]. This particular microclimate is found in subterranean habitats all year round [8,9]; accordingly, stable populations of Hydromantes are often found in these habitats, where they can reach high abundances [2]. Additionally, besides the high environmental suitability, subterranean habitats generally lack predators ([10]; but see [11,12] for a few exceptions), a condition allowing Hydromantes salamanders to select these habitats for their long reproductive period [13].

Feeding ecology is an ecological trait of these salamanders that has recently received special attention. The absence of lungs in Hydromantes enabled the evolution of a protrusible tongue that is used to catch a wide range of prey [6,14,15]. Indeed, Hydromantes mostly adopt a sit-and-wait hunting strategy, waiting until suitable prey come within reach of the tongue, which can be extended up to $80 \%$ of the salamander's body length [16,17]. Prey diversity in Hydromantes is high, ranging from flying insects to aquatic larvae, comprising at least 35 different invertebrate orders [15,18,19]. Moreover, the se salamanders often "recycle" their own organic matter such as unfertilized eggs or the skin after moulting [15]. Foraging activity is more intense during spring and fall [15,19,20], seasons in which the appropriate climatic conditions allow to leave the subterranean refuges and exploit outdoor environments, where prey availability is higher [21,22]. Following prey capture, salamanders return to their refuges where suitable microclimatic conditions ensure effective cutaneous respiration but also promote digestion $[7,23,24]$. A comparative study including six European Hydromantes species (H. ambrosii, $H$. flavus, $H$. supramontis, $H$. imperialis, $H$. sarrabusensis and $H$. genei) indicated that, although few prey categories account for the highest proportion of food items in all of them, a difference in diet composition between these species occurs [25]. No differences in diet composition and prey diversity occurred between adults and juveniles, but the latter usually consumed fewer and smaller prey, a constraint likely due to their size $[25,26]$. However, the authors did not assess any potential intraspecific divergence in diet composition.

Individual diet specialization (IS) occurs when individuals use a subset of prey types included in the population's trophic niche [26,27]. As a consequence, the niche width of the population is determined by both the intra-individual dietary diversity, and by the variability of prey types in the diet of the different individuals [28,29]. IS has major impacts on population stability, interspecific interactions and food web structure [30,31]; nevertheless the occurrence of IS has been evaluated only for a limited number of species (see [32-34] for some examples). The presence of individual specialisation in the use of trophic resources has been assessed in most of the European Hydromantes. Within the six studied species (H. strinatii, H. flavus, H. supramontis, H. imperialis, H. sarrabusensis and H. genei) each population had "true specialists", although in different proportions [35-37]. Individuals may specialise to use a subset of the available resources as a consequence of negative biological interactions, because a high prey diversity promotes individuals' preference, or of both conditions acting synergistically $[26,38]$. The refore, the full spectrum of resources consumed by a population (the total niche width) can be explained by the variability of the resources consumed by each individual (within-individual component), but it also includes the diversity occurring between individuals (between-individual component), as they can significantly differ from each other in the use of the available resources $[27,39,40]$. Individual diet specialization refers to the trophic strategy adopted by the single individuals regardless of age, sex or any other morphological constraint [31,33]. The studies conducted on Hydromantes indicated that the overall generalism of the species was due to a higher contribution of specialised individuals [35-37]. Beside the important preliminary information provided, some of these studies were limited in time (i.e., a single season [36]) and space (i.e., a single population [35]), a condition limiting the knowledge on the potential variability occurring among conspecific populations [37]. 
The aim of the present study was to perform an in-depth analysis of the trophic habits of the Ambrosi's cave salamander, H. ambrosii, which is one of the two Hydromantes species in which the individual diet specialization has never been explored before. Although the analysis is performed on one species, the re are very few studies investigating the individual variability of the feeding habits in multiple populations of the same species [37,41,42]), leaving a knowledge gap related to the potential variability occurring among conspecific populations. The stomach content of individuals from three Ligurian populations (NW Italy), collected in spring and fall, was analysed to test whether the dietary habits varied spatially and seasonally, and whether sexual, ontogenetic or size-related factors are playing a role. Two different methodological approaches were adopted to analyse these data: the first was based on conventional multivariate procedures, while the second relied on the estimation of niche metrics and two indices of individual specialization [27]. Specifically, we verified whether different populations showed comparable trophic niches and whether they were characterised by a similar proportion of specialised individuals. The analyses were repeated in spring and fall to assess whether the characteristics of populations' trophic niches change according to the season. In addition, we considered a diverse set of population features (i.e., body condition and density) as well as the environmental characteristics of the foraging area of the populations (i.e., vegetation cover of the cave surroundings) to evaluate their potential effects on the salamanders' trophic niches.

\section{Methods}

\subsection{Study Species and Data}

Hydromantes ambrosii is one of the eight species of European plethodontids, and its range occurs between Liguria and Tuscany, in north-western Italy [2]. The data analysed here were published by Lunghi et al. (2018) [15], reporting the stomach contents of a total of 124 individuals of $H$. ambrosii (67 females, 42 males and 15 juveniles) obtained from three different caves located in the La Spezia Province (Liguria, Italy; Figure 1) in 2016 and 2017; salamanders with empty stomach (38) and with only one prey item (31) were not considered in the analysis. The caves were far from the hybrid zone between $H$. ambrosii and the Italian cave salamander, H. italicus [4]; therefore, no congeneric (or hybrid) competitors occurred in the study area. Two of the surveyed sites (Populations 2 and 3) were relatively close (linear distance of about $180 \mathrm{~m}$; Figure 1). Despite these sites being not far from each other, the available data suggest that the dispersal of Hydromantes mostly occurs over shorter distances $(<100 \mathrm{~m})$ [43,44]. Maximum dispersal distances $<100 \mathrm{~m}$ are frequent in plethodontid salamanders [45]; consequently, we assumed the three populations to be independent.

Three samplings were performed, two in spring (2016 and 2017) and one in fall (2016). The sample size was relatively small and, to be able to employ all three populations in our analysis, we assumed that no seasonal niche breath variation occurred in the populations between different years (spring 2016 vs. 2017), thus we merged spring data to analyse at least 9 individuals for each population. Multiple samplings were performed to increase the robustness of the collected data $[37,47]$. Populations were haphazardly sampled as salamanders cannot be individually recognised. The study populations are very large (about 80 individuals for Population 3 and hundreds for Populations 1 and 2; [48]) and, under these conditions, the recapture rate of Hydromantes is, on average, $~ 0.5$ [48]; therefore, repeated samplings of the same individuals were unlikely. A high rate of pseudo-replication would have happened if populations were repeatedly sampled during the same period, with a consequent increase in biased results. We are confident that the single seasonal survey performed here avoided this problem. Captured salamanders were stomach flushed and measured (snout-vent length (SVL), in $\mathrm{mm}$ ) [15]; all salamanders showing an SVL $<40 \mathrm{~mm}$ were considered juveniles, while for adults, the sex was assessed basing on the presence/absence of male secondary sexual characteristics [2]. 


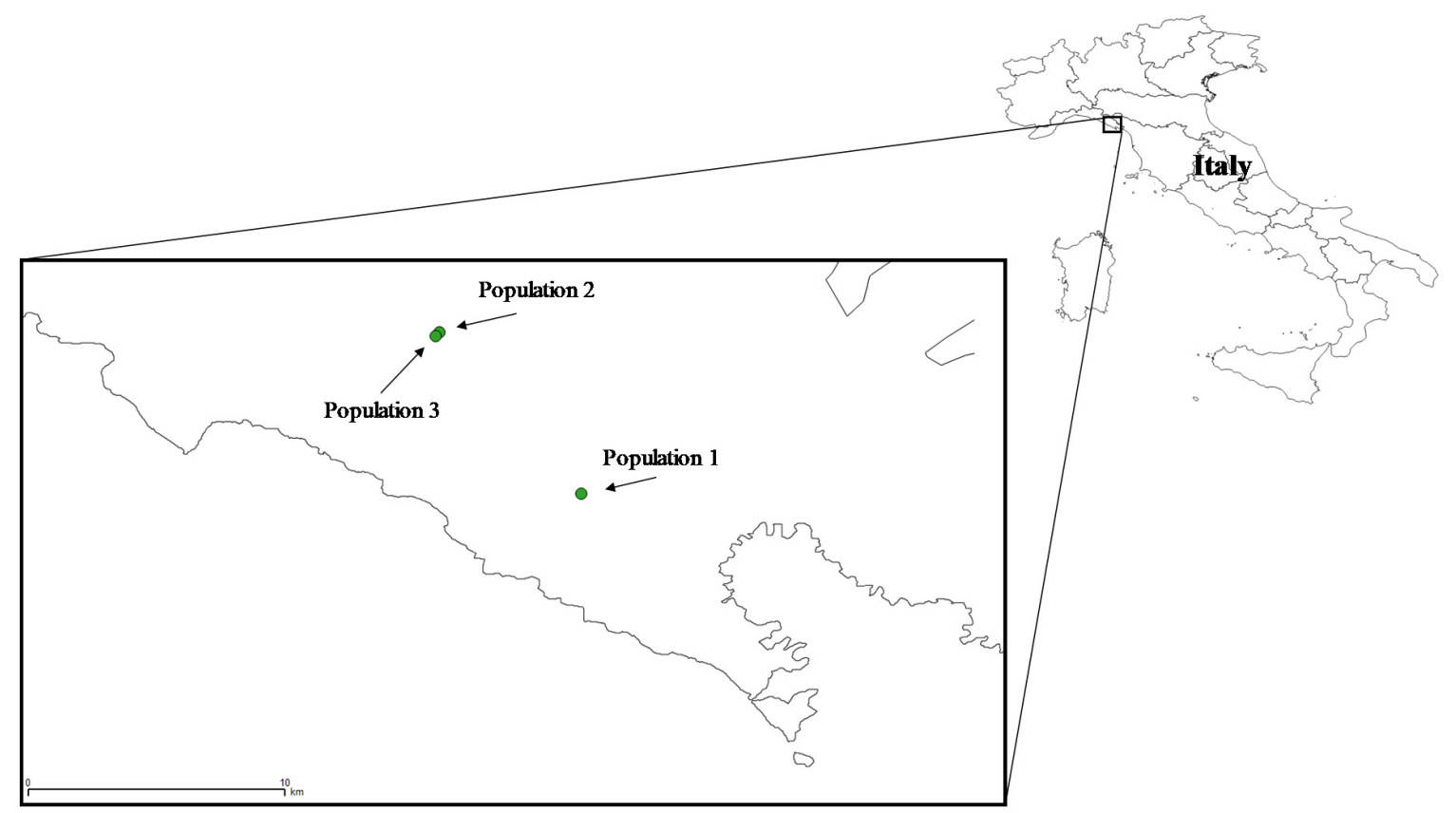

Figure 1. Location of the three studied populations of Hydromantes ambrosii. Green circles indicate the monitored caves. Further details are not shown for species protection [46].

Prey items were generally identified at the order level, and when possible, different life stages or specific families were also considered as independent groups, obtaining data related to 381 prey items belonging to 30 different prey groups [15]. All vertebrate food items were pooled into a single prey type (Hydromantes), and the prey categories were reduced to 28. Stomach contents always contained a certain amount of unidentified items for which a further prey category has been created. Only salamanders with at least two different prey categories in their stomachs were included in the analyses, to reduce the overestimation of individual specialization indices (see further in this section; [27]).

During the last survey (spring 2017), prior to undergoing stomach flushing, 74 randomly captured salamanders $(24.67 \pm 12.66$ salamanders per cave; females $=37$, males $=23$, juveniles $=14$ ) were measured in their total length (TL) and weighed (electronic scale, $0.01 \mathrm{~g}$ ) to estimate their body condition index (hereafter, BCI). Only non-gravid females were used to estimate the BCI [13]. As the $\mathrm{BCI}$, we used the Residual index [49,50]; residuals (i.e., the difference between the observed and the expected body mass) were estimated according to a log-log relationship between salamanders' weights and sizes. In this analysis we used the total length as these salamanders usually store fat in the tail [51].

Estimates of the abundance of these populations were obtained using $\mathrm{N}$-mixture models, on the basis of repeated counts performed in spring 2017 [48]. For details on sampling procedures, data analyses and the reliability of the abundance estimates see reference [48].

We used these estimations to assess the density of the three populations (as abundance/surveyed area in $\mathrm{m}^{2}$ ). In addition, the coordinates of the three $H$. ambrosii populations were used to extract quantitative information on the arboreal and non-arboreal vegetation cover (expressed in \%) of the cave surroundings (area with diameter pixel size of $250 \mathrm{~m}$ ) from the Terra MODIS Vegetation Continuous Field (VCF) product (available as MOD44B v006 at https://pdaac.usgs.gov/products/mod44bv006/) for the years 2016 and 2017. Despite being not far from each other, Populations 2 and 3 are in an area with strong topographic and habitat heterogeneity and fall in different pixels of the MODIS vegetation maps. Arboreal vegetation cover included all forest types and age classes, while non-arboreal vegetation cover included meadows, regeneration areas and clear-cut areas. 


\subsection{Statistical Analysis}

We used non-metric multi-dimensional (nMDS) analysis to explore the dietary similarity among the three populations under analysis. A two-way permutational multivariate analysis of variance (PERMANOVA with 10,000 permutations) was subsequently performed to test for the effects of the factor "season" (fixed, two levels, "spring" and "fall") and "ontogenetic stage" (fixed, two levels, "adult" and "juvenile") with the SVL of individual salamanders as a continuous covariate. PERMANOVA tests were repeated for adults only, verifying the influence of sex.

A population's total niche width (TNW) was calculated using the measure proposed by Roughgarden [52], based on the Shannon-Weaver diversity index:

$$
\mathrm{TNW}=-\sum_{j} q_{j} \ln q_{j}
$$

where $q_{j}$ is the frequency of prey category $j$ in the population's niche. TNW equals zero when all the individuals in the population consume only one single prey category and increases with both the number of prey categories and the evenness with which they are consumed. For each population, together with TNW, two additional niche metrics were estimated, i.e., the within- and between-individual components (WIC and BIC, respectively; $[28,29]$ ). In brief, the total niche width (TNW) of a population is assumed to be determined by the interaction of intra-individual variations in resource use (WIC), measured by the average variance of individuals' utilization functions $\rho(x \mid y)$ along a continuous dimension $x$

$$
\mathrm{WIC}=\overline{\operatorname{VAR}[\rho(x \mid y)]}
$$

and of inter-individual variations in resource use (BIC), measured by the variance of the frequency distribution for different individual averages in the population:

$$
\mathrm{BIC}=\overline{\operatorname{VAR}[p(y)]}
$$

where $p(y)$ is the frequency distribution of individuals with average use $y$ in the population. Accordingly, the total niche width TNW represents the variance of the population's resource-utilization function $\mathrm{H}(x)$ and equals the sum of BIC and WIC [29]:

$$
\mathrm{TNW}=\operatorname{VAR}[H(x)]=W I C+B I C
$$

The metrics were originally developed for a single continuous variable $x$, released from any assumption of normality regarding the functional form of $p(y)$ and $\rho(x \mid y)$, and were subsequently implemented for the discrete case [52].

The ratio WIC/TNW was used to estimate the populations' degree of individual specialization $[27,28]$; a WIC/TNW close to one indicates a population of generalists, while a ratio close to zero indicates the dominance of specialist individuals.

Given that we had only one BIC, WIC, TNW and WIC/TNW value per combination population/ season (see Results for further detail), we tested for differences in niche metrics by bootstrapping (see [53] for details). In brief, for each combination, we randomly sampled with replacement $n$ individuals, where $n$ corresponds to the sample size of the group. The procedure was repeated 999 times; the bootstrapped values had their distributions centred on the original values of the metrics, and differences were tested using a two-way ANOVA with season and population as orthogonal fixed factors. Similarly, Monte Carlo resampling simulations (9999 permutations) were used to evaluate if the degree of individual specialization WIC/TNW determined for each combination population/season was significantly different from that expected by a null scenario hypothesizing that all individuals sample equally from the population diet distribution. To test for correlations between pairwise size and diet similarity indices, a Mantel test with 9999 permutations was run. 
A second index of individual diet specialisation was also considered; the individual specialisation (IS). This index was calculated as:

$$
\mathrm{IS}=\frac{\sum_{i} P S_{i}}{N}
$$

where $N$ is the number of $i$ individuals in a population, while the proportional similarity index $\left(P S_{i}\right)$ was estimated using the methodology proposed by Bolnick et al. [27]:

$$
P S_{i}=1-0.5 \sum_{j}\left|p_{i j}-q_{j}\right|
$$

where $p_{i j}$ is the frequency of a prey category $j$ in the individual $i$ 's diet, and $q_{j}$ is the frequency of prey category $j$ in the entire population. We express values in the text as averages \pm SE unless otherwise specified; for parametric statistical analysis, we tested data for conformity to the assumptions of variance homogeneity (Cochran's C test) and normality (Shapiro-Wilk test), and we log-transformed variables when required. All statistical analyses were performed in the R environment [54]. Specifically, the package $R I n S p$ (v. 1.2.3) was used for niche metrics analysis and related resampling procedures [53], vegan (v. 2.5-6; [55]) for nMDS and PERMANOVA analyses, and ade4 (v. 1.7-13; [56]) for Mantel tests.

\section{Results}

At two sites (Populations 1 and 2) the proportion of arboreal vegetation cover was higher than the non-arboreal one, while in the third site (Population 3), the opposite occurred (Table 1). No significant difference in the arboreal cover was observed among the three sites; however, when considering the non-arboreal cover, Population 3 had a significantly higher proportion compared to the other two (Table 1).

Table 1. Location of the three Hydromantes ambrosii populations analysed in the study. Latitudes and longitudes are reported with a downgraded precision to increase species protection [46]. Information on elevation (m a.s.l.) are included, together with estimations of arboreal and non-arboreal vegetation cover (expressed in \%) of the cave's surrounding areas. Vegetation variables were extracted from Terra MODIS VCF tiles (see text for further details) and, in the table, are averaged over the years 2016 and 2017 (SE in brackets). F values refer to the results of one-way ANOVAs testing for differences among the three locations, considering the years 2016 and 2017 as replicates. ${ }^{*}=p<0.05$. The results of post-hoc Tukey HSD tests are also reported.

\begin{tabular}{cccccc}
\hline & Population 1 & Population 2 & Population 3 & $\mathbf{F}_{2,3}$ & HSD \\
\hline Longitude & 9.77 & 9.72 & 9.72 & & \\
Latitude & 44.12 & 44.18 & 44.17 & & \\
Elevation & 331 & 206 & 260 & & \\
Arboreal vegetation & $55.3(3.6)$ & $53.2(3.5)$ & $45.75(1.85)$ & 2.63 & $1=2=3$ \\
Non-arboreal vegetation & $38(0.4)$ & $34.1(2.6)$ & $47.1(1.4)$ & $14.58 *$ & $1=2<3$ \\
\hline
\end{tabular}

The nMDS plot of salamanders' stomach content data highlighted a considerable similarity in the dietary habits among the three populations of Hydromantes ambrosii (Figure 2); in contrast, independently from the population, salamanders showed a remarkably different diet when spring and fall were compared (Figure 2). PERMANOVA analyses confirmed that "season" significantly influenced salamanders' dietary habits, while negligible differences were found between populations, between ontogenetic stages or sexes, or between individuals of different size (Table 2). 


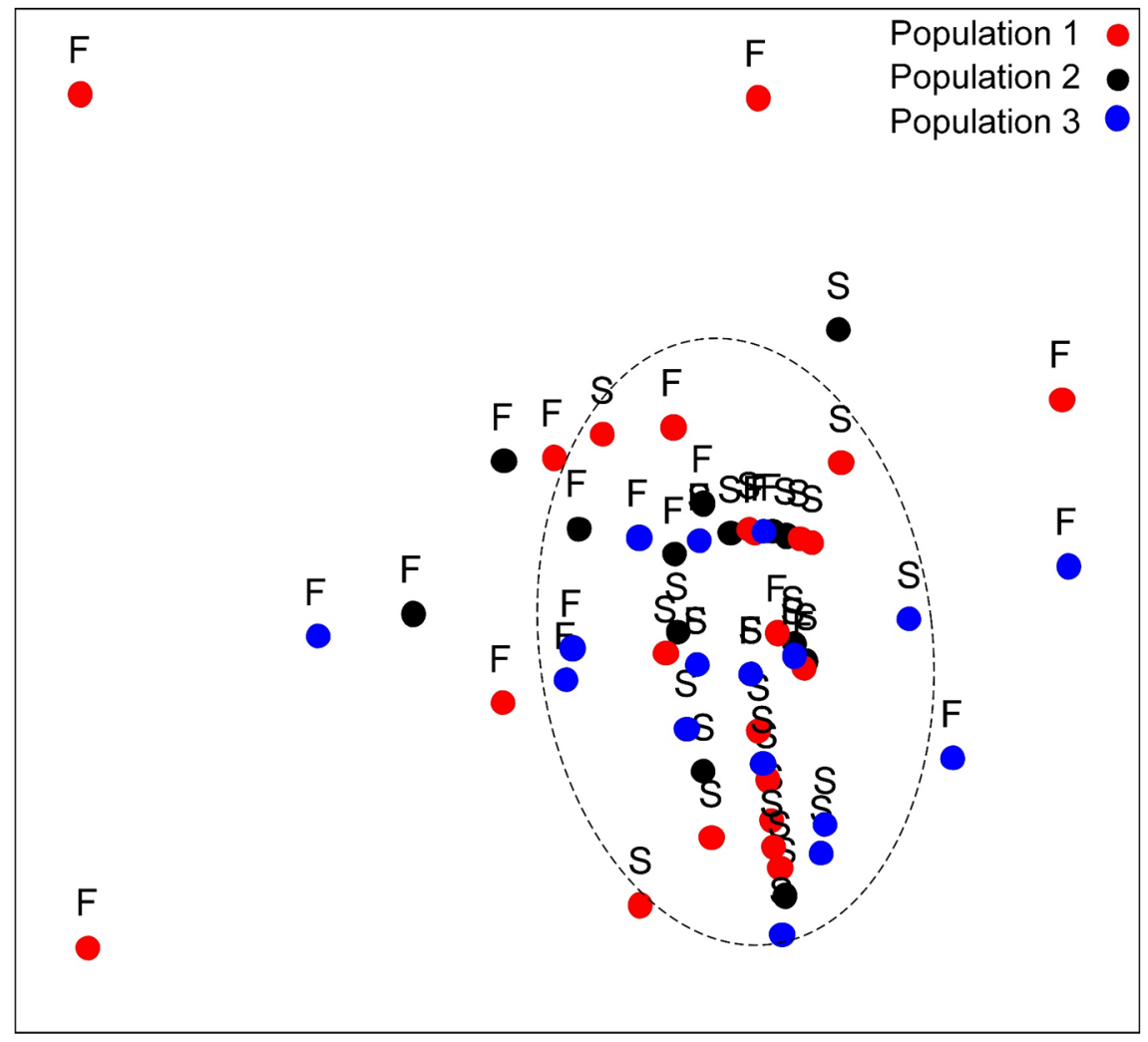

2D Stress: 0.08

Figure 2. Non-metric multidimensional scaling plots (nMDS) of stomach content data of the three H. ambrosii populations. Letters indicate seasons ( $\mathrm{F}=$ fall, $\mathrm{S}=$ spring). A $95 \%$ confidence ellipse is plotted around the spring data.

Table 2. Seasonal, age/sex and body size-related effects on stomach content data values across the three analysed Hydromantes ambrosii populations: results of PERMANOVA run on Euclidean distances calculated on log-transformed data and performed under a reduced model using 9999 permutations. $p(\mathrm{MC})=p$-value obtained by the Monte Carlo permutation test. The table reports the significance of factors, also testing pairwise interactions. On the left side are shown results considering all salamanders, and on the right side, those considering adults only; factor three represents age for all salamanders and sex for adults only. nd = factor or interaction not tested due to unbalanced design; $S V L=$ snout-vent length .

\begin{tabular}{ccccc}
\hline \multirow{2}{*}{ Factor } & \multicolumn{2}{c}{ All Salamanders } & \multicolumn{2}{c}{ Adult Only } \\
\cline { 2 - 5 } & Pseudo-F & $\boldsymbol{p}$ (MC) & Pseudo-F & $p(\mathbf{M C})$ \\
\hline (1) SVL & 0.91 & 0.454 & 0.54 & 0.781 \\
(2) Population & 1.23 & 0.246 & 0.99 & 0.444 \\
(3) Age/Sex & 1.5 & 0.175 & 1.5 & 0.164 \\
(4) Season & 16.03 & 0.001 & 14.07 & 0.001 \\
$(1) \times(2)$ & 1.14 & 0.328 & 1.16 & 0.28 \\
$(1) \times(3)$ & 1.64 & 0.124 & 0.29 & 0.976 \\
$(1) \times(4)$ & 0.77 & 0.570 & 1.14 & 0.308 \\
$(2) \times(3)$ & 0.44 & 0.981 & 0.70 & 0.755 \\
$(2) \times(3)$ & 0.67 & 0.788 & 0.75 & 0.702 \\
$(3) \times(4)$ & 1.25 & 0.257 & 1.92 & 0.077 \\
$(1) \times(2) \times(3)$ & 1.25 & 0.258 & 0.95 & 0.469 \\
$(1) \times(2) \times(4)$ & 1.65 & 0.067 & 1.45 & 0.142 \\
$(1) \times(3) \times(4)$ & 0.48 & 0.846 & 2.02 & 0.045 \\
$(2) \times(3) \times(4)$ & nd & - & 1.82 & 0.19 \\
$(1) \times(2) \times(3) \times(4)$ & nd & - & nd & - \\
\hline
\end{tabular}


Niche metric analysis provided a more advanced resolution of the trophic characteristics of the three populations. In fall, BIC, WIC and TNW were approximately twice as large as in spring, independently of population (Table 3; two-way ANOVA, factor "season", $p<0.05$ for both metrics), yet none showed seasonally consistent patterns of variation among populations (for all metrics, $p$ always $<0.001$ for the interaction factor "season $\times$ population"). In particular, in spring, Population 3 had the highest WIC followed by Populations 1 and 2, and BIC decreased from Population 1 to 3, while Population 1 showed the widest niche followed by Populations 3 and 2 (Table 3; post-hoc Tukey HSD tests, $p$ always $<0.05)$. Conversely, in fall, WIC increased from Population 1 to 3 , and Population 2 showed the highest BIC compared to the other two populations (HSD tests, $p$ always $<0.05$ ), while Population 1 was characterised by the narrowest niche compared to those of Populations 2 and 3 (HSD tests, $p<0.05$ ), which show similar widths (HSD test, $p=0.09$ ). The WIC/TNW ratio was characterised by a more consistent pattern among seasons (Figure 3). Independently from the season, salamanders from Populations 2 and 3 showed the highest and lowest degrees of individual specialization, respectively (HSD tests, $p$ always $<0.01$ ). Additionally, only Population 2 had, in both seasons, a WIC/TNW ratio significantly different from that expected by a null scenario, where all individuals sample equally from the pool of prey items of the population. Population 1 was characterised by an intermediate level of specialization, even though it was not significantly different from that of Population 2 in spring (HSD test, $p=0.11$ ). The individual specialisation index (IS) was similar among the three populations and indicated a general higher proportion of specialised individuals in fall; however, the se indices were not statistically significant (Table 3).

The difference observed in the salamanders' condition index (BCI) among the studied populations was quite evident (Figure 4). In spring, individuals from Population 3 showed a low dietary specialization and were characterised by the highest BCI; contrarily, although Populations 1 and 2 had similar higher proportions of specialised individuals, the ir BCI dramatically differed (Figure 4). Interestingly, the patterns observed for the BCI values of the three populations partially replicated those of the vegetation characteristics of the cave surroundings: thus, Population 2 was associated with conditions of minimum non-arboreal and maximum arboreal cover, while the vegetation characteristics of the Population 3 cave surroundings showed the opposite (Table 1).

Table 3. Summary of trophic niche metrics and number of analysed individuals per season (in square brackets) of the three Hydromantes ambrosii populations. WIC = within-individual component; $\mathrm{BIC}=$ between-individual component; TNW = total niche width; IS = individual specialisation. $95 \%$ bootstrapped confidence intervals are in round brackets. The estimated density ( $\mathrm{N}$ individuals $/ \mathrm{m}^{2}$ ) and, within parentheses, the total population size estimated by Ficetola et al. [48] of each population are included. ${ }^{\dagger} p>0.20$.

\begin{tabular}{|c|c|c|c|c|}
\hline \multicolumn{2}{|c|}{ Season } & \multirow{2}{*}{$\begin{array}{c}\text { Population } 1 \\
{[3 \mathrm{~F}, 6 \mathrm{~J}]}\end{array}$} & \multirow{2}{*}{$\begin{array}{c}\text { Population } 2 \\
{[12 \mathrm{~F}, 4 \mathrm{M}]}\end{array}$} & \multirow{2}{*}{$\begin{array}{l}\text { Population } 3 \\
{[4 \mathrm{~F}, 4 \mathrm{M}, 2 \mathrm{~J}]}\end{array}$} \\
\hline Fall & & & & \\
\hline & WIC & $1.394(1.38-1.408)$ & $1.482(1.471-1.493)$ & $1.729(1.718-1.741)$ \\
\hline & $\mathrm{BIC}$ & $0.859(0.853-0.866)$ & $1.126(1.118-1.135)$ & $0.864(0.858-0.87)$ \\
\hline & TNW & $2.253(2.24-2.267)$ & $2.608(2.598-2.618)$ & $2.594(2.581-2.606)$ \\
\hline & IS & $0.442^{+}$ & $0.340^{\dagger}$ & $0.427^{\dagger}$ \\
\hline \multirow[t]{6}{*}{ Spring } & & {$[22 \mathrm{~F}, 14 \mathrm{M}, 6 \mathrm{~J}]$} & {$[17 \mathrm{M}, 15 \mathrm{M}, 1 \mathrm{~J}]$} & {$[9 \mathrm{~F}, 5 \mathrm{M}]$} \\
\hline & WIC & $0.684(0.681-0.686)$ & $0.603(0.6-0.606)$ & $0.799(0.795-0.802)$ \\
\hline & $\mathrm{BIC}$ & $0.517(0.509-0.524)$ & $0.451(0.444-0.458)$ & $0.338(0.334-0.343)$ \\
\hline & TNW & $1.201(1.192-1.209)$ & $1.054(1.046-1.062)$ & $1.137(1.129-1.145)$ \\
\hline & IS & $0.728^{+}$ & $0.699^{+}$ & $0.738^{+}$ \\
\hline & Density & $0.422(144.5)$ & 0.144 (137.2) & $0.106(67.1)$ \\
\hline
\end{tabular}




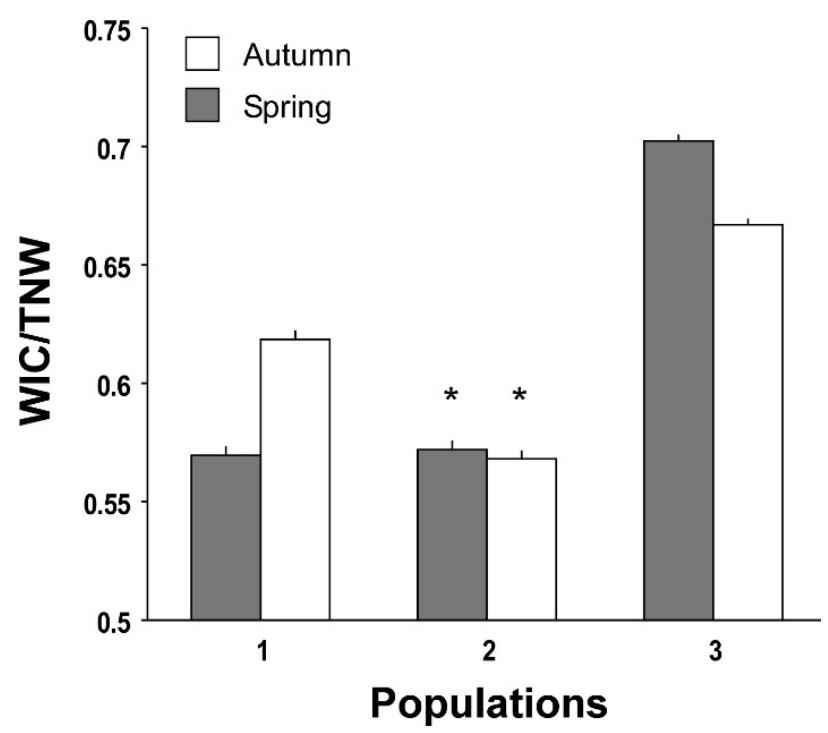

Figure 3. The ratio Within-Individual Component/Total Niche Width. Asterisks indicate that the ratios are significantly different from those expected by a null scenario hypothesising that all individuals sample equally from the population pool of prey items.

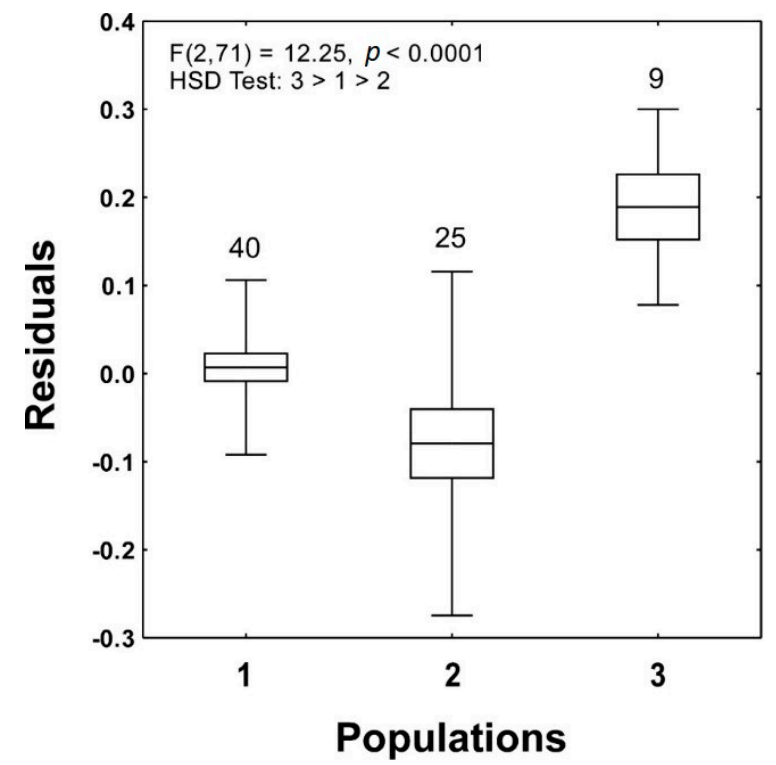

Figure 4. Variation in body condition across the three H. ambrosii populations. Boxes represent the ranges between first and third quartiles, horizontal bars inside the boxes represents the means, and whiskers embrace the full spectrum of data. Numbers on the tops of the whiskers represent the number of analysed salamanders. Top left: the results of one-way ANOVA and Tukey HSD tests assessing the significant difference among populations.

\section{Discussion}

Overall, in the present study, conventional multivariate statistical analyses indicated that the prey items consumed by the three Hydromantes ambrosii populations showed significant seasonal variations; however, negligible among-population effects were detected, suggesting that $H$. ambrosii salamanders may be characterised by dietary habits that are the same across the different localities. However, the analysis of the trophic niche metrics confirmed the importance of seasonality in the dietary habits of these salamanders, providing a far more advanced resolution of the actual among-population differences. 
The total niche width (TNW) was about twice as wide in fall than in spring for all the three populations (Figure 2), confirming observations on other Hydromantes species [25,35]. The increase in the populations' trophic niche likely reflects a parallel increase in the diversity and availability of prey; indeed, the majority of the invertebrate taxa consumed by Hydromantes hibernate during winter and reproduce during spring/summer [57]. Thus, in fall, the re is probably a higher invertebrate diversity with the co-occurrence of different life stages, a condition increasing prey availability for Hydromantes salamanders $[15,38]$. The effect of seasonality on TNW was highly population-specific, with Population 2 showing the strongest variation, followed by Populations 3 and 1; similarly, both the intra- and inter-individual variation in the consumed prey items (WIC and BIC) varied significantly and unpredictably among populations and between seasons (Table 3). However, WIC was always higher than BIC (Table 2), indicating the prevalence of generalist individuals independently from the population. This was confirmed by the generally high values of the individual specialization index (WIC/TNW); however, only for Population 2 the comparison of the index against a null expectation was statistically significant in both spring and fall (Figure 3), indicating that this population may include "true specialist" individuals that do not randomly prey upon the available prey. A general lack of "true specialists" was also confirmed by the individual specialisation index (IS), which was never significantly different from the null hypothesis (Table 3). Only salamanders from Population 2 maintain a well-defined trophic strategy independently from seasonal variations in biotic constraints determined by, for example, density- or resource-dependent factors $[26,38]$. The se results are quite interesting as in the other six Hydromantes species for which dietary specialization was assessed [35-37]; all populations showed a significant large proportion of "true specialists". Conversely, in H. ambrosii, all populations were mostly composed of generalist individuals, and only one had a significant proportion of specialists (Figure 3). It is not clear if such a dominant generalism only characterises H. ambrosii, or if it is the result of particular environmental conditions acting locally. Future studies are needed to shed light on this particular topic.

The pattern of variation observed for the WIC/TNW ratio in spring (Figure 3) needs to be discussed considering the densities and body condition indices of the three populations, as well as differences in environmental conditions between the sites. Individuals from Population 2 showed a low body condition index and a relatively high degree of specialization (for both WIC/TNW and IS), while Population 3 showed a completely opposite pattern. Generally, when the density of a population is high, limited resources increase negative intraspecific interactions, and the energy consumption induced by competition leads to a general reduction in the body conditions of individuals [58,59]. In our case, Populations 2 and 3 showed the lowest and highest body conditions, respectively (Figure 4), although had similar estimated densities (Table 3; 0.14 vs. 0.11 individuals $/ \mathrm{m}^{2}$ ). One possible explanation for this inconsistency may rely be a difference in ecological opportunity characterising the outdoor surroundings of the caves. Hydromantes are not strictly cave species and forage close to the cave's entrance or in the surroundings, where prey are more abundant $[8,21]$. There, ecological opportunity (i.e., local prey abundance and diversity; [38]) is likely to be correlated with vegetation cover, the latter providing shelter, food resources and microclimatic conditions suitable for a multitude of invertebrate species $[60,61]$ as well as salamanders. The arboreal vegetation showed limited variation across the three study sites; nevertheless, the outdoor surroundings of Population 2 were characterised by non-arboreal vegetation cover significantly lower than that of Population 3 (Table 1). This may also reflect a lower ecological opportunity in terms of prey abundance and, in turn, salamanders' body condition indices. Alternatively, the slightly lower arboreal vegetation cover characterising Population 3 might limit the microclimate suitable for invertebrates during dry periods, and these species likely seek shelter in the first few meters inside caves [8]. The refore, Hydromantes do not have to exit their refuge to prey, thus saving energy and reducing the stress due to less suitable environmental conditions and higher predation risks [10,22]. The se interesting hypotheses need to be tested as no data on prey abundance and diversity were available. 
Negative biotic interactions (interspecific or intraspecific) are further processes potentially increasing the number of specialized individuals within a population, as those characterised by the weakest competitive abilities may reduce the width of their trophic niches as they only focus on sub-optimal food resources to avoid competition $[32,62,63]$. Interspecific competition is probably not playing an important role, since all Hydromantes species show allopatric distributions, and thus no more than one species occurs in the same area [2]. The only exception is the narrow contact zone between H. ambrosii and H. italicus, where hybrid populations occur [4]; however, the studied populations are located far from this hybrid zone. Moreover, no other Caudata are known to regularly exploit subaerial cave habitats, and thus competition with equivalent species can be ruled out. Competition might occur with some gecko species, as these reptiles can inhabit the areas close to the cave entrance [64]; still, geckos generally select dry microhabitats while Hydromantes select humid microhabitats [5], thus these species can hardly compete. Furthermore, interspecific competition with some cave invertebrates, although negligible and mostly affecting juvenile salamanders, cannot be excluded [11]. On the other hand, the occurrence of intraspecific competition in Hydromantes has not been yet assessed and the few available pieces of information are contrasting $[65,66]$. Hydromantes salamanders are facultative cave species seeking subterranean environments as a suitable place to escape the adverse climatic conditions occurring outside of the cave (too hot or dry) [2]. The se species show a narrow microclimatic niche and select only cave areas falling within their tolerance range [5,9]. Thus, only specific areas of the caves can be occupied, a condition potentially leading to high densities [2,21]. However, we did not find signs of negative intraspecific competition. Indeed, during spring season, Population 1 had a much better BCI than Population 2 (Figure 4), although the former has a density of salamanders around three times higher, and the two have basically the same WIC/TNW ratio (Table 3). On the other hand, Population 3, although having a density comparable to that of Population 2 (Table 3), had higher a proportion of generalist individuals and BCI. The picture described here is drawn with information related to spring only, a season in which Hydromantes are extremely active [9,21], but we do not know if this pattern remains the same in fall. The refore, further studies involving different species and seasons will help in confirming the lack of intraspecific competition observed here within the whole genus.

Noticeably, Population 2 showed the lowest mean BCI with the highest variance, suggesting that further factors may affect salamanders' conditions. This population inhabits a touristic cave; thus, disturbance produced by humans may cause stress to salamanders, altering their activity, with negative cascade effects on individuals' body conditions $[21,67,68]$. Indeed, an increase in salamanders' activity was observed in H. flavus (Sardinia, Italy) after gate-limited touristic activities in a cave (Manuela Mulargia, personal communication). Although specific data are not yet available, future studies are needed to confirm this hypothesis.

Nevertheless, our study has some limitations. The limited sample size of the dataset did not allow the assessment of the potential variation in the seasonal populations' niche breath across different years. To keep the highest possible number of analysed individuals, we assumed that the seasonal populations' niche breath did not significantly change among different years. This assumption deserves further confirmation through the analysis of multiple individuals collected over several years. Finally, two surveyed sites were spatially close $(<180 \mathrm{~m})$, and vegetation cover was estimated using a radius of $125 \mathrm{~m}$ around each site; thus, buffers partially overlapped. Although being partially non-independent, the differences in vegetation between these sites remained appreciable.

In conclusion, the present study provides new information on the dietary habits of H. ambrosii. Contrarily to most of the previous studies, in the present one, we focused on single populations to assess potential divergences occurring among conspecific populations. Such a kind of fine scale analysis highlighted significant variation in the trophic niche and degree of individual specialization among conspecific populations living close to each other. This helps to identify the potential drivers of divergences among populations' dynamics, the refore providing information to guide the implementation of ecologically meaningful conservation plans. Furthermore, the preponderance of generalist individuals observed among the studied populations is clearly in contrast with what already 
observed for other congeneric species [35-37]; this scenario deserves to be further investigated. This will necessarily include, in addition to the classic analysis of the stomach contents, other complementary methodologies such as stable isotope analysis $[69,70]$, which will provide more complete information on the trophic ecology of this taxon.

Author Contributions: E.L. and G.M. conceived the idea, analyzed the data, wrote the first draft of the manuscript and prepared tables and figures; All authors have read and agreed to the published version of the manuscript.

Funding: Grant (NSFC-31972868) from the National Natural Science Foundation of China to Yahui Zhao.

Acknowledgments: We thank Sebastiano Salvidio for the invitation to contribute to this special issue. Fieldwork was authorized by the Italian Ministry of Environment (Prot. 9384/PNM-12/05/2015 and Prot. N. 20624/PNM-30/09/ 2016). E.L. is supported by the Chinese Academy of Sciences President's International Fellowship Initiative for postdoctoral researchers (2019PB0143). The final version of this paper has been concluded during a sabbatical year of one the authors (G.M.) in the Department of Chemistry, Biology, and Biotechnology, University of Perugia (Italy), and is dedicated to Sofia Mancinelli, thy eternal summer shall not fade.

Conflicts of Interest: The authors declare no conflicts of interest. The funder had no role in the design of the study; in the collection, analyses, or interpretation of data; in the writing of the manuscript, or in the decision to publish the results.

\section{References}

1. Wake, D.B. The enigmatic history of the European, Asian and American plethodontid salamanders. Amphib. Reptil. 2013, 34, 323-336. [CrossRef]

2. Lanza, B.; Pastorelli, C.; Laghi, P.; Cimmaruta, R. A review of systematics, taxonomy, genetics, biogeography and natural history of the genus Speleomantes Dubois, 1984 (Amphibia Caudata Plethodontidae). Atti. Mus. Civ. Stor. Nat. Trieste 2006, 52, 5-135.

3. Chiari, Y.; van der Meijden, A.; Mucedda, M.; Lourenço, J.M.; Hochkirch, A.; Veith, M. Phylogeography of Sardinian cave salamanders (genus Hydromantes) is mainly determined by geomorphology. PLoS ONE 2012, 7, e32332. [CrossRef] [PubMed]

4. Ficetola, G.F.; Lunghi, E.; Cimmaruta, R.; Manenti, R. Transgressive niche across a salamander hybrid zone revealed by microhabitat analyses. J. Biogeogr. 2019, 46, 1342-1354. [CrossRef]

5. Ficetola, G.F.; Lunghi, E.; Canedoli, C.; Padoa-Schioppa, E.; Pennati, R.; Manenti, R. Differences between microhabitat and broad-scale patterns of niche evolution in terrestrial salamanders. Sci. Rep. 2018, 8, 10575. [CrossRef] [PubMed]

6. Bruce, R.C.; Jaeger, R.G.; Houck, L.D. (Eds.) The Biology of Plethodontid Salamanders; Springer Science+Business Media, LLC: New York, NY, USA, 2000. [CrossRef]

7. Spotila, J.R. Role of temperature and water in the ecology of lungless salamanders. Ecol. Monogr. 1972, 42, 95-125. [CrossRef]

8. Culver, D.C.; Pipan, T. (Eds.) The Biology of Caves and Other Subterranean Habitats, 2nd ed.; Oxford University Press: New York, NY, USA, 2019.

9. Lunghi, E.; Manenti, R.; Ficetola, G.F. Seasonal variation in microhabitat of salamanders: Environmental variation or shift of habitat selection? PeerJ 2015, 3, e1122. [CrossRef]

10. Salvidio, S.; Palumbi, G.; Romano, A.; Costa, A. Safe caves and dangerous forests? Predation risk may contribute to salamander colonization of subterranean habitats. Sci. Nat. 2017, 104, 20. [CrossRef]

11. Pastorelli, C.; Laghi, P. Predation of Speleomantes italicus (Amphibia: Caudata: Plethodontidae) by Meta menardi (Arachnida: Araneae: Metidae). In Atti del $6^{\circ}$ Congresso Nazionale della Societas Herpetologica Italica (Roma, 27.IX-1.X.2006); Museo Regionale di Scienze Naturali: Torino, Italy, 2006; pp. 45-48.

12. Manenti, R.; Lunghi, E.; Canedoli, C.; Bonaccorsi, M.; Ficetola, G.F. Parasitism of the leech, Batracobdella algira (Moquin-Tandon, 1846), on Sardinian cave salamanders (genus Hydromantes) (Caudata: Plethodontidae). Herpetozoa 2016, 29, 27-35.

13. Lunghi, E.; Corti, C.; Manenti, R.; Barzaghi, B.; Buschettu, S.; Canedoli, C.; Cogoni, R.; De Falco, G.; Fais, F.; Manca, A.; et al. Comparative reproductive biology of European cave salamanders (genus Hydromantes): Nesting selection and multiple annual breeding. Salamandra 2018, 54, 101-108.

14. Deban, S.M.; Dicke, U. Motor control of tongue movement during prey capture in Plethodontid salamanders. J. Exp. Biol. 1999, 202, 3699-3714. [PubMed] 
15. Lunghi, E.; Cianferoni, F.; Ceccolini, F.; Mulargia, M.; Cogoni, R.; Barzaghi, B.; Cornago, L.; Avitabile, D.; Veith, M.; Manenti, R.; et al. Field-recorded data on the diet of six species of European Hydromantes cave salamanders. Sci. Data 2018, 5, 180083. [CrossRef] [PubMed]

16. Deban, S.M.; Dicke, U. Activation patterns of the tongue-projector muscle during feeding in the imperial cave salamander Hydromantes imperialis. J. Exp. Biol. 2004, 207, 2071-2081. [CrossRef] [PubMed]

17. Deban, S.M.; Richardson, J.C. Cold-Blooded snipers: Thermal independence of ballistic tongue projection in the salamander Hydromantes platycephalus. J. Exp. Zool. 2011, 315, 618-630. [CrossRef] [PubMed]

18. Vignoli, L.; Caldera, F.; Bologna, M.A. Trophic niche of cave populations of Speleomantes italicus. J. Nat. Hist. 2006, 40, 1841-1850. [CrossRef]

19. Salvidio, S.; Romano, A.; Oneto, F.; Ottonello, D.; Michelon, R. Different season, different strategies: Feeding ecology of two syntopic forest-dwelling salamanders. Acta Oecol. 2012, 43, 42-50.

20. Salvidio, S. Diet and food utilization in the European plethodontid Speleomantes ambrosii. Vie et Milieu 1992, 42, 35-39.

21. Lunghi, E.; Manenti, R.; Mulargia, M.; Veith, M.; Corti, C.; Ficetola, G.F. Environmental suitability models predict population density, performance and body condition for microendemic salamanders. Sci. Rep. 2018, 8, 7527. [CrossRef]

22. Jiménez-Valverde, A.; Sendra, A.; Garay, P.; Reboleira, A.S.P.S. Energy and speleogenesis: Key determinants of terrestrial species richness in caves. Ecol. Evol. 2017, 7, 10207-10215. [CrossRef]

23. Crump, M.L. Intra-population variability in energy parameters of the salamander Plethodon cinereus. Oecologia 1979, 38, 235-247. [CrossRef]

24. Marvin, G.A.; Bryan, R.; Hardwick, J. Effect of chronic low body temperature on feeding and gut passage in a plethodontid salamander. J. Therm. Biol. 2017, 69, 319-324. [CrossRef] [PubMed]

25. Lunghi, E.; Cianferoni, F.; Ceccolini, F.; Veith, M.; Manenti, R.; Mancinelli, G.; Corti, C.; Ficetola, G.F. What shapes the trophic niche of European plethodontid salamanders? PLoS ONE 2018, 13, e0205672. [CrossRef] [PubMed]

26. Bolnick, D.I.; Svanbäck, R.; Fordyce, J.A.; Yang, L.H.; Davis, J.M.; Hulsey, C.D.; Forister, M.L. The ecology of individuals: Incidence and implications of individual specialization. Am. Nat. 2003, 161, 1-28. [CrossRef] [PubMed]

27. Bolnick, D.I.; Yang, L.H.; Fordyce, J.A.; Davis, J.M.; Svanbäck, R. Measuring individual-level resource specialization. Ecology 2002, 83, 2936-2941. [CrossRef]

28. Roughgarden, J. Evolution of niche width. Am. Nat. 1972, 106, 683-718. [CrossRef]

29. Roughgarden, J. Niche width: Biogeographic patterns among Anolis lizard populations. Am. Nat. 1974, 108, 429-442. [CrossRef]

30. Bolnick, D.I.; Amarasekare, P.; Araújo, C.S.; Bürger, R.; Levine, J.M.; Novak, M.; Rudolf, V.H.W.; Schreiber, S.J.; Urban, M.C.; Vasseur, D.A. Why intraspecific trait variation matters in community ecology. Trends Ecol. Evol. 2011, 26, 183-192. [CrossRef]

31. Layman, C.A.; Newsome, S.D.; Crawford, T.G. Individual-level niche specialization within populations: Emerging areas of study. Oecologia 2015, 178, 1-4. [CrossRef]

32. Svanbäck, R.; Bolnick, D.I. Intraspecific competition drives increased resource use diversity within a natural population. Proc. R. Soc. B 2007, 274, 839-844. [CrossRef]

33. Araújo, M.S.; Bolnick, D.I.; Martinelli, L.A.; Giaretta, A.A.; dos Reis, S.F. Individual-level diet variation in four species of Brazilian frogs. J. Anim. Ecol. 2009, 78, 848-856. [CrossRef]

34. Terraube, J.; Guixé, D.; Arroyo, B. Diet composition and foraging success in generalist predators: Are specialist individuals better foragers? Basic Appl. Ecol. 2014, 15, 616-624. [CrossRef]

35. Salvidio, S.; Oneto, F.; Ottonello, D.; Costa, A.; Romano, A. Trophic specialization at the individual level in a terrestrial generalist salamander. Can. J. Zool. 2015, 93, 79-83. [CrossRef]

36. Salvidio, S.; Pasmans, F.; Bogaerts, S.; Martel, A.; van de Loo, M.; Romano, A. Consistency in trophic strategies between populations of the Sardinian endemic salamander Speleomantes imperialis. Anim. Biol. 2017, 67, 1-16. [CrossRef]

37. Lunghi, E.; Manenti, R.; Cianferoni, F.; Ceccolini, F.; Veith, M.; Corti, C.; Ficetola, G.F.; Mancinelli, G. Inter-specific and inter-population variation in individual diet specialization: Do environmental factors have a role? Ecology 2020. [CrossRef] 
38. Araújo, M.S.; Bolnick, D.L.; Layman, C.A. The ecological causes of individual specialisation. Ecol. Lett. 2011, 14, 948-958. [CrossRef]

39. Araujo, M.S.; dos Reis, S.F.; Giaretta, A.A.; Machado, G.; Bolnick, D.I. Intrapopulation diet variation in four frogs (Leptodactylidae) of the Brazilian savannah. Copeia 2007, 2007, 855-865. [CrossRef]

40. Pyke, G.H.; Pullian,H.R.; Charnov, E.L. Optimal foraging: A selective review of theory and tests. Quart. Rev. Biol. 1977, 52, 137-154. [CrossRef]

41. Quiroga, M.F.; Bonansea, M.I.; Vaira, M. Population diet variation and individual specialization in the poison toad, Melanophryniscus rubriventris (Vellard, 1947). Amphib. Reptil. 2011, 32, 261-265. [CrossRef]

42. Rosenblatt, A.E.; Nifong, J.C.; Heithaus, M.R.; Mazzotti, F.J.; Cherkiss, M.S.; Jeffery, B.M.; Elsey, R.M.; Decker, R.A.; Silliman, B.R.; Guillette, L.G.J.; et al. Factors affecting individual foraging specialization and temporal diet stability across the range of a large "generalist" apex predator. Oecologia 2015, 178, 5-16. [CrossRef]

43. Lunghi, E.; Bruni, G. Long-term reliability of Visual Implant Elastomers in the Italian cave salamander (Hydromantes italicus). Salamandra 2018, 54, 283-286.

44. Salvidio, S. Homing behaviour in Speleomantes strinatii (Amphibia Plethodontidae): A preliminary displacement experiment. North West. J. Zool. 2013, 9, 429-433.

45. Smith, M.A.; Green, D.M. Dispersal and the metapopulation paradigm in amphibian ecology and conservation: Are all amphibian populations metapopulations? Ecography 2005, 28, 110-128. [CrossRef]

46. Lunghi, E.; Corti, C.; Manenti, R.; Ficetola, G.F. Consider species specialism when publishing datasets. Nat. Ecol. Evol. 2019, 3, 319. [CrossRef] [PubMed]

47. Novak, M.; Tinker, M.T. Timescales alter the inferred strength and temporal consistency of intraspecific diet specialization. Oecologia 2015, 178, 61-74. [CrossRef] [PubMed]

48. Ficetola, G.F.; Barzaghi, B.; Melotto, A.; Muraro, M.; Lunghi, E.; Canedoli, C.; Lo Parrino, E.; Nanni, V.; Silva-Rocha, I.; Urso, A.; et al. N-mixture models reliably estimate the abundance of small vertebrates. Sci. Rep. 2018, 8, 10357. [CrossRef]

49. Băncilă, R.I.; Hartel, T.; Plăiaşu, R.; Smets, J. Cogălniceanu, D. Comparing three body condition indices in amphibians: A case study of yellow-bellied toad Bombina variegata. Amphib. Reptil. 2010, 31, 558-562. [CrossRef]

50. Labocha, M.K.; Schutz, H.; Hayes, J.P. Which body condition index is best? Oikos 2014, 123, 111-119. [CrossRef]

51. Scott, D.E.; Casey, E.D.; Donovan, M.F.; Lynch, T.K. Amphibian lipid levels at metamorphosis correlate to post-metamorphic terrestrial survival. Oecologia 2007, 153, 521-532. [CrossRef]

52. Roughgarden, J. Theory of Population Genetics and Evolutionary Ecology; Macmillan Publishing Company: New York, NY, USA, 1979; p. 612.

53. Zaccarelli, N.; Bolnick, D.I.; Mancinelli, G. RInSp: An R package for the analysis of individual specialization in resource use. Methods Ecol. Evol. 2013, 4, 1018-1023. [CrossRef]

54. R: A Language and Environment for Statistical Computing; R Foundation for Statistical Computing: Vienna, Austria. Available online: http://www.R-project.org/ (accessed on 18 September 2019).

55. Oksanen, J.; Blanchet, F.G.; Friendly, M.; Kindt, R.; Legendre, P.; McGlinn, D.; Minchin, P.R.; O’Hara, R.B.; Simpson, G.L.; Solymos, P.; et al. Vegan: Community Ecology Package. R Package Version 2.5-6. Available online: http://cran.r-project.org/web/packages/vegan (accessed on 28 January 2020).

56. Dray, S.; Dufour, A.B. ade4: Analysis of Ecological Data - Exploratory and Euclidean Methods in Environmental Sciences. Available online: https://CRAN.R-project.org/package=ade4 (accessed on 28 January 2020).

57. Bale, J.S.; Hayward, S.A.L. Insect overwintering in a changing climate. J. Exp. Biol. 2010, 213, 980-994. [CrossRef]

58. Kirk, D.A.; Gosler, A.G. Body condition varies with migration and competition in migrant and resident south American vultures. Auk 1994, 111, 933-944. [CrossRef]

59. Petren, K.; Case, T.J. Habitat structure determines competition intensity and invasion success in gecko lizards. Proc. Natl. Acad. Sci. USA 1998, 95, 11739-11744. [CrossRef] [PubMed]

60. Baur, B.; Cremene, C.; Groza, G.; Schileyko, A.A.; Baur, A.; Erhardt, A. Intensified grazing affects endemic plant and gastropod diversity in alpine grasslands of the Southern Carpathian mountains (Romania). Biologia 2007, 62, 438-445. [CrossRef]

61. Norbury, G.; Heyward, R.; Parkes, J. Skink and invertebrate abundance in relation to vegetation, rabbits and predators in a New Zealand dryland ecosystem. N. Z. J. Ecol. 2009, 33, 24-31. 
62. Tinker, M.T.; Bentall, G.; Estes, J.A. Food limitation leads to behavioral diversification and dietary specialization in sea otters. Proc. Natl. Acad. Sci. USA 2008, 105, 560-565. [CrossRef] [PubMed]

63. Araújo, M.S.; Costa-Pereira, R. Latitudinal gradients in intraspecific ecological diversity. Biol. Lett. 2013, 9, 20130778. [CrossRef] [PubMed]

64. Nguyen, H.N.; Lu, C.-W.; Chu, J.-H.; Grismer, L.L.; Hung, C.-M.; Lin, S.-M. Historical demography of four gecko species specializing in boulder cave habitat - its implications in the evolutionary dead end hypothesis and conservation. Mol. Ecol. 2019, 28, 772-784. [CrossRef] [PubMed]

65. Salvidio, S.; Pastorino, M.V. Spatial segregation in the European plethodontid Speleomantes strinatii in relation to age and sex. Amphib. Reptil. 2002, 23, 505-510.

66. Ficetola, G.F.; Pennati, R.; Manenti, R. Spatial segregation among age classes in cave salamanders: Habitat selection or social interactions? Pop. Ecol. 2013, 55, 217-226. [CrossRef]

67. Cejuela Tanalgo, K.; Tabora, J.A.G.; Hughes, A.C. Bat cave vulnerability index (BCVI): A holistic rapid assessment tool to identify priorities for effective cave conservation in the tropics. Ecol. Indic. 2018, 89, 852-860. [CrossRef]

68. Whitten, T. Applying ecology for cave management in China and neighbouring countries. J. Appl. Ecol. 2009, 46, 520-523. [CrossRef]

69. Cloyed, C.S.; Eason, P.K. Niche partitioning and the role of intraspecific niche variation in structuring a guild of generalist anurans. R. Soc. Open Sci. 2017, 4, 170060. [CrossRef] [PubMed]

70. Costa-Pereira, R.; Rudolf, V.H.W.; Souza, F.L.; Araújo, M.S. Drivers of individual niche variation in coexisting species. J. Anim. Ecol. 2018, 87, 1452-1464. [CrossRef] [PubMed]

(C) 2020 by the authors. Licensee MDPI, Basel, Switzerland. This article is an open access article distributed under the terms and conditions of the Creative Commons Attribution (CC BY) license (http://creativecommons.org/licenses/by/4.0/). 